\title{
NovoTTF-200A Device
}

National Cancer Institute

\section{Source}

National Cancer Institute. NovoTTF-200A Device. NCI Thesaurus. Code C141439.

A second generation tumor treatment field (TTF; TT Field) device. 